\title{
La Laborem Exercens: Encíclica del diálogo y de la esperanza renovadores
}

\section{El Evangelio Del tRABAJO}

«El Evangelio del trabajo» es una expresión original y singular que aparece por primera vez en un documento del magisterio ${ }^{1}$. Su contenido se convierte en el hilo conductor de toda la reflexión de la encíclica y también cohesiona su estilo poco sistemático, a pesar de que dicha expresión no aparece más que en seis ocasiones, con referencia a etapas fundamentales de la revelación divina y en las que el Papa precisa, breve y concisamente, cuáles son las fuentes, el contenido y las. finalidades que se propone con la lectura y comentario de este Evangelio del trabajo.

\section{A. Fuentes del Evangelio del trabajo:}

$1 .^{\circ}$ La obra creadora de Dios: El relato de la creación, que hace el Génesis, es leído bajo la perspectiva de el «Trabajo» realizado por Dios durante «seis días» para descansar el «séptimo» $(25 / 2)$ y concluye: «Esta descripción

1. TALIERcio, G., «Il primato dell'uomo nella Laborem Exercens»: Palestra del Clero 61 (1982) 175-176; FERRARO, G., «Aspetti teologici dell'enciclica Laborem Exercens»: Aggiornamenti Sociali 32 (1981) 670-671. «La originalidad y singularidad de la expresión, juntamente con su frecuencia y el contenido teológico y cristológico que le da el Papa, confirman la derivación fundamental de principios teológicos de la doctrina expuesta en la encíclica» (FERRARo, G., a.c.). «El Evangelio del trabajo se propone anunciar aquellas verdades contenidas en la Biblia que iluminan el sentido más profundo de esta fatiga humana y que afirman el valor y la dignidad del trabajo hasta su sublimación en Cristo, en cuanto que también el trabajo humano es asumido en su misterio pascual y concurre, a su modo, a la llegada de aquella «tierra nueva» en la que habitará la justicia» (REINA, M., «Per una introduzione alla enciclica Laborem Exercens»: Aggiornamenti Sociali 32 (1981) 653; SCHASCHING, J., «L'uomo e il lavoro»: Rassegna di Teologia 23 (1982) 6-9; HiguerA, G., «Sed solidarios. El pensamiento social de Juan Pablo II en España»: Sal Terrae 70 (1982) $767-780$. 
de la creación, que encontramos ya en el primer capítulo del libro del Génesis es, a su vez, en cierto sentido el Evangelio del trabajo» (253).

$2 .^{\circ}$ La persona de Cristo, a su vez, «pone particularmente de relieve» este Evangelio del trabajo, no tanto con lo que ha dicho como con lo que ha vivido y actuado.

«En efecto, Jesús no solamente anunciaba, sino que ante todo, cumplía con el trabajo el «Evangelio» confiado a él, la palabra de la Sabiduría eterna. Por consiguiente, esto era también el «Evangelio del trabajo», pues el que lo proclamaba era él mismo hombre de trabajo, del trabajo artesano al igual que José de Nazaret... la elocuencia de la vida de Cristo es inequívoca: pertenece al «mundo del trabajo, tiene reconocimiento y respeto por el trabajo humano; se puede decir incluso más: Él mira con amor el trabajo, sus diversas manifestaciones, viendo en cada una de ellas un aspecto particular de la semejanza del hombre con Dios, Creador y Padre» (26/1).

$3 .^{\circ}$ La doctrina de $S$. Pablo es «un importante, aunque discreto complemento».

«Las enseñanzas del Apóstol de las Gentes tienen, como se ve, una importancia capital para la moral y la espiritualidad del trabajo humano. Son un importante complemento a este grande, aunque discreto, Evangelio del trabajo, que encontramos en la vida de Cristo y en sus parábolas, en lo que Jesús «hizo y enseñó» (26/4).

\section{4. ${ }^{\circ}$ El mismo proceso productivo}

«La antinomia entre el trabajo y el capital no tiene su origen en la estructura del mismo proceso de producción, y ni siquiera en la del proceso económico en general. Tal proceso demuestra en efecto la compenetración recíproca entre el trabajo y lo que estamos acostumbrados a llamar el capital; demuestra su vinculación indisoluble» $(13 / 2)^{2}$.

5. ${ }^{\circ}$ Las ciencias humanas: También las ciencias contribuyen a delimitar y desarrollar la eficacia del Evangelio del trabajo. De ellas asume el Evangelio del trabajo la descripción de la «situación general del hombre en el mundo

2. Es Evangelio del trabajo porque si bien se aplica a la realidad concreta y tiene en cuenta las aportaciones de las ciencias humanas, sin embargo su fuente fundamental lo es la Palabra de Dios y la reflexión que de ella dinama. De entre todos los elementos que contribuyen a la formulación del Evangelio del trabajo predomina la Palabra de Dios, que, «cuando es rectamente interpretada nunca deja de ser actual»: $4 / 3 ; 3 / 1,5 ; 5 / 5 ; 6 / 1 ; 7 / 1 ; 11 / 1 ; 10 / 4 ; 12 / 2 ; 13 / 2 ; 24 / 1 ; 25$; $26 / 5 ; 27 / 2,7$. 
contemporáneo, considerada y analizada en sus varios aspectos geográficos, de cultura y civilización...» (2/1); "el diagnóstico de la realidad social objetiva» (3/1); el «exacto reconocimiento objetivo del estado de las cosas» (2/4); el «significado objetivo del trabajo» (6/1). También las tiene en cuenta en lo referente a las consecuencias que seguirán a los múltiples e importantes cambios que se operan en el mundo del trabajo. «Cambios que podrán quizás significar por desgracia, para millones de trabajadores especializados, desempleo, al menos temporal, o necesidad de nueva especialización; conllevarán niuy probablemente una disminución o crecimiento menos rápido del bienestar material para los países más desarrollados; pero podrán también proporcionar respiro y esperanza a millones de seres que viven hoy en condiciones de vergonzosa e indigna miseria» (1/3). En tales campos la Iglesia no se siente competente y confía su estudio a los hombres de ciencia, porque «no corresponde a la iglesia analizar científicamente las posibles consecuencias de tales cambios en la convivencia humana» (1/4).

Tales aportaciones de las ciencias delimitan el ámbito propicio en que pueden encarnarse los valores defendidos por el Evangelio del trabajo, el ritmo que pueden seguir el acercamiento al ideal, que son esos valores, y las dificultades que encuentra, exigiendo al mismo tiempo «una continua puesta al día» de las conclusiones arrojadas por la confrontación entre los valores defendidos por el Evangelio del trabajo y las circunstancias concretas en las que deben hacerse realidad. Es lo que nos indica la misma encíclica: «Este patrimonio tradicional -el contenido del Evangelio del trabajo- ha sido después heredado y desarrollado por las enseñanzas de los Pontífices sobre la moderna «cuestión social», empezando por la encíclica Rerum Novarum. En el contexto de esta «cuestión», la profundización del problema del trabajo ha experimentado una continua puesta al día conservando siempre aquella base cristiana de verdad que podemos llamar perenne» $(3 / 1)$.

\section{B. Contenido y destinatarios}

En cuanto al contenido del Evangelio del trabajo algunas afirmaciones de la encíclica pueden servirnos de orientación general, como marco amplio dentro del cual se mueve. Así nos advierte que el Evangelio del trabajo lo constituyen «esas afirmaciones básicas sobre el trabajo que han surgido siempre de la riqueza de la verdad cristiana especialmente del mensaje mismo del «Evangelio del trabajo» (7/1); o «la misma estructura portadora de la enseñanza de la Iglesia que se mantiene sin cambios a través de los siglos, en el contexto de las diversas experiencias de la historia» (11/1); "aquella base cristiana de verdad que podemos llamar perenne», ese «patrimonio tradicional que después 
ha sido heredado y desarrollado por las enseñanzas de los Pontífices sobre la moderna «cuestión social», empezando por la encíclica Rerum Novarum... con una «profundización del problema del trabajo», que expérimenta una «continua puesta al día conservando siempre aquella base cristiana de verdad que podemos llamar perenne» (3/2).

A modo de indicación quizás pudiéramos esquematizar ese Evangelio del trabajo como sigue:

I. Concepción del hombre: $4 / 2,3 / 1$

a.- El hombre, imagen de Dios en el contexto de la creación: $4 / 2,4 ; 6 / 2$; $8 / 2 ; 9 / 1 ; 25 / 1,2 ; 26 ; 27$

b.- Para que domine la tierra y cuanto en ella se contiene: $4 / 2,3 ; 5 / 1,2,3$; $7 / 4 ; 8 / 2 ; 9 / 1,2 ; 10 / 4 ; 12 / 1 ; 13 / 1$

c.- Sujeto del trabajo: $5 / 3,6 ; 6 / 1,2,3,6 ; 7 / 3,4 ; 8 / 1,2,6 ; 9 / 1 ; 12 / 5,6$; $13 / 2,4 ; 17 / 3 ; 18 / 4 ; 23 / 1$.

II. Trabajo

a.- Dimensión fundamental del hombre: Introducción; $9 / 3 ; 11 / 1,6 ; 16 / 2$

b.- Dignidad del trabajo como realidad humana: $6 / 6 ; 7 / 2 ; 8 / 6 ; 11 / 1$; $21 / 3 ; 23 / 3 ; 24 / 1 ; 26$

c.- Orientada hacia el bien del hombre: $3 / 3 ; 5 / 4 ; 6 / 2 ; 6 / 6 ; 8 / 3 ; 11 / 1$;

$13 / 5 ; 14 / 3 ; 15 / 1,2 ; 16 / 1 ; 17 / 1,4,5 ; 18 / 1,3 ; 19 / 1,4 ; 20 ; 21 ; 22 ; 23 ; 26 / 5$

d.- Participación en la obra creadora de Dios: $25 ; 26$.

III. Relaciones trabajo-capital

a.- Unidad indivisible entre trabajo y capital: $11 / 3,4 ; 13 / 1,2,3,4,5$; $14 / 1,3 ; 15 / 1 ; 20 / 3$

b.- Predominio del hombre sobre el capital: $7 / 2 ; 12 / 1,4,5,6$; $13 / 2,3,4,5 ; 14 / 4,7 ; 18 / 4 ; 21 / 3 ; 22$.

c.- Predominio del trabajo sobre el capital: $12 / 1,4,5,6 ; 13 / 1 ; 14 / 4,7$; $15 / 1 ; 17 / 3 ; 18 / 5$

d.- Predominio de la dimensión subjetiva del trabajo sobre su dimensión objetiva: $6,3,5 ; 7 / 3 ; 10 / 4 ; 11 / 3 ; 14 / 4 ; 22 / 1,3$

IV. Espiritualidad del trabajo: $24-27$

V. Concepción de la vida social: $3 / 1 ; 17 ; 18 ; 22 / 2$.

Desde otro punto de vista puede hablarse de un núcleo del Evangelio del trabajo dirigido a todos los hombres de buena voluntad, sean cristianos o no, constituido por «los interrogantes esenciales que se refieren al trabajo humano en relación con el sujeto, que es precisamente el hombre. Estos interrogantes, en cuanto que «encierran una carga particular de contenidos y tensiones de carácter ético y ético-social. Por ello constituyen un desafío continuo para múltiples instituciones, para los Estados y para los gobiernos, para los sistemas y las organizaciones internacionales; constituyen también un desafío para 
la Iglesia» (5/6); todo aquel conjunto de derechos del hombre cuya violación constituye «una degradación del hombre como sujeto del trabajo» que desató, en su día, la llamada «cuestión proletaria» como «justa reacción social» (8 y 20). Desde este punto de vista el contenido del Evangelio del trabajo se centra en la proposición «del justo orden de valores» $(4 / 3 ; 6 / 3,4,5 ; 7)$, como alternativa al economicismo y materialismo y como visión grandiosa y profundamente humana del trabajo, ya que todo ello se resume en la obligación de hacerse más hombre EN el trabajo y MEDIANTE el trabajo (7/1) ${ }^{3}$.

Una segunda parte, dirigida particularmente a los cristianos convencidos que viven su fe en el compromiso temporal, gira toda ella en torno a ese «otro aspecto del trabajo humano», a «esa dimensión suya esencial» en la que la espiritualidad, fundada sobre el Evangelio del trabajo, penetra profundamente $(27 / 1)$, puesto que «en el trabajo humano el cristiano descubre una pequeña parte de la cruz de Cristo y la acepta con el mismo espíritu de redención, con el cual Cristo ha aceptado su cruz por nosotros. En el trabajo, merced a la luz que penetra dentro de nosotros por la resurrección de Cristo, encontramos siempre un tenue resplandor de la vida nueva, y del nuevo bien, casi como un anuncio de los nuevos cielos y otra tierra nueva»... (27/5). Anuncia todas aquellas verdades contenidas en la Biblia que iluminan el sentido más profundo de la fatiga humana y afirman el valor y la dignidad hasta su sublimación en Cristo, en cuanto que también el trabajo humano está íntimamente asumido en su misterio pascual de muerte y resurrección y concurre a su modo a la preparación de la llegada de aquella «nueva tierra» en la que habitará definitivamente la justicia $(27 / 4,5)$.

En esta parte se esfuerza en ayudarnos a comprender el trabajo en su aspecto cristológico y teándrico, en el aspecto de la participación humana mediante el trabajo en el misterio pascual: «Al hombre entero se dirige también la Palabra del Dios vivo, el mensaje evangélico de la salvación en el que encontramos muchos contenidos - como luces particulares - dedicados al trabajo humano. Ahora bien, es necesaria una adecuada asimilación de estos contenidos; hace falta el esfuerzo interior del espíritu humano, guiado por la fe, la esperanza y la caridad, con el fin de dar al trabajo del hombre concreto, con la ayuda de estos contenidos, aquel significado que el trabajo tiene ante los ojos de Dios, y mediante el cual entra en la obra de la salvación al igual que sus tramas y componentes ordinarios, que son al mismo tiempo particularmente importantes» $(24 / 1)$, porque la Iglesia «ve un deber suyo particular en la formación de una espiritualidad del trabajo, que ayude a todos los hombres

3. Herrero, Z., «La Laborem Exercens: Encíclica del diálogo y de la esperanza renovadores»: Estudio Agustiniano 18 (1983) 371ss. 
a acercarse a través de él a Dios, Creador y Redentor, a participar en sus planes salvíficos respecto al hombre y al mundo, y a profundizar en sus vidas la amistad con Cristo, Profeta, y Rey, tal como lo enseña con expresiones admirables el Concilio Vaticano II» (24/2).

La encíclica «no es un tratado de derecho natural, ni un documento político o económico», sino «un juicio sobre la política o sobre la economía hecho desde el hombre tal como es visto por la palabra de Dios» con una finalidad muy clara: la radical transformación del actual orden social político con el fin de restituir al hombre trabajador su centralidad. Frente al economicismo y materialismo subraya el contenido teológico y cristológico, cuidadosamente deducido de los principios revelados. El matiz profundo y ampliamente religioso se echa de ver en el puesto preeminente de las citas bíblicas que copan 71 notas de las 91 que tiene la encíclica. Ello resalta más aún cuando se la compara con las otras encíclicas sociales entre las que encontramos 28 notas bíblicas en la Rerum Novarum, 30 en la Quadragessimo Anno, 25 en la Pacem in Terris y 7 en la Octogessima Adveniens. En la Laborem Exercens predomina de tal manera el aspecto religioso que renuncia explícitamente al análisis de las cuestiones técnicas $(1 / 3,4)$ para reflexionar «según la orientación del Evangelio» $(2 / 1)^{4}$. Por ello algún autor la califica de «meditación religiosa», aunque sin dejar de ser un acto formal del magisterio ${ }^{5}$.

El Evangelio del trabajo va dirigido a las masas de los trabajadores explotados, a las estructuras y centros de poder que imponen condiciones, a veces, inhumanas al trabajo del hombre; se dirige a los pueblos ricos y a sus empresas multinacionales y también al nuevo «maravilloso banco del trabajo moderno» actualizado con la más avanzada tecnología «fruto del patrimonio histórico del trabajo,humano» (21/4). La comunidad cristiana se ve comprometida en la difusión del Evangelio del trabajo.

\section{Finalidad del Evangelio del trabajo}

El Evangelio del trabajo se propone, como finalidad «crear el fundamento del nuevo modo humano de pensar, de valorar y de actuar» $(7 / 1)$. Y lo presenta, convencido de que los actuales adelantos y los ya próximos «que, según

4. ReINA, M., «Per una introduzione alla enciclica Laborem Exercens«: Aggiornamenti Sociali 32 (1981) 653; TALIERCIO, «Il primato dell'uomo nella Laborem Exercens»: Palestra del Clero 61 (1982) 180-181; GARCí, M., «Conceptos claves de la Laborem Exercens» en AA.VV., Juan Pablo II y la justicia social, Razón y Fe, Madrid 1982,25; UNCITI, M. de, «Primera aproximación a la Encíclica»: Iglesia Viva (1982/97-98) 7.

5. ReINA, M., «Per una introduzione alla enciclica Laborem Exercens»: Aggionamenti Sociali 32 (1981) 654 . 
muchos expertos, influirán en el mundo del trabajo y de la producción no menos de cuanto lo hizo la revolución industrial del siglo pasado»... «harán necesaria una reorganización y revisión de las estructuras de la economía actual, así como de la distribución del trabajo» (1/3). Tales cambios de no ir adecuadamente orientados y dirigidos por una gran estima de la dignidad de la persona humana se convertirán en «desgracia» y sufrimiento para millones de personas (1/3). Estas consecuencias solamente se evitarán con «un nuevo modo humano de pensar, de valorar y de actuar» (7/1). Modo nuevo de pensar etc. si lo confrontamos con los principios dominantes en los sistemas económicos vigentes. Novedad que se fija como objetivos: el «descubrir nuevos significados y nuevos cometidos del trabajo humano» (2/1); defender la dignidad y los derechos de los hombres del trabajo y denunciar las situaciones de injusticia (1/4), en definitiva el Evangelio del trabajo se dinamiza en la lucha por la justicia considerando la cuestión social «en su dimensión integral y compleja» y convencido de que «el compromiso en favor de la justicia debe estar íntimamente unido con el compromiso en favor de la paz en el mundo contemporáneo») $(2 / 2)$.

A este respecto llama la atención la concepción dinámica de la justicia que se transparenta a lo largo de toda la encíclica. No admite el estancamiento de la reflexión en catálogos trasnochados de formas de injusticia, puesto que «un análisis completo de la situación de la justicia en el mundo contemporáneo ha puesto de manifiesto de modo todavía más profundo y más pleno el significado del análisis anterior de las injusticias sociales; y es el significado que hoy se debe dar a los esfuerzos encaminados a construir la justicia sobre la tierra, no escondiendo con ello las estructuras injustas, sino exigiendo un examen de las mismas y su transformación en una dimensión más universal» $(2 / 4)$. Una injusticia que, en este mismo número, parece tener un test de comprobación «la igualdad» y no sólo a nivel nacional sino también internacional $(2 / 4)$. Ello es posible porque «la profundización del problema del trabajo ha experimentado una constante puesta al día» $(3 / 1)$, puesto que se trata de una justicia que conservando siempre aquella base cristiana de verdad que podemos llamar perenne... se elabora «según las necesidades de las distintas épocas» $(3 / 1)^{6}$.

Descubrir nuevas injusticias porque el realismo de la Laborem Exercens, que tiene en cuenta los condicionamientos de la realidad objetiva, es consciente de que «la solución de la cuestión social es una solución gradual», que en cada etapa se presenta de manera nueva y cada vẹ se hace más compleja $(3 / 2)$.

6. Cfr. $8 / 6 ; 10 / 4$. 


\section{El materialismo a la luz del Evangelio del trabajo}

La misma encíclica contrapone el Evangelio del trabajo al economicismo y materialismo de los sistemas imperantes. Después de haber enunciado las ideas claves del Evangelio del trabajo concluye: «En la época moderna, desde el comienzo de la era industrial, la verdad cristiana sobre el trabajo debía contraponerse a las diversas corrientes del pensamiento materialista y economicista» (7/1); economicismo y materialismo que se hacen realidad oprimente y agresiva en ambos sistemas: capitalismo y socialismo (13).

1. La mentalidad economicista-materialista ofrece una visión econocimista del trabajo. Lo considera «exclusivamente según su finalidad económica» $(13 / 3)$; ofrece «un planteamiento no humanista» $(13 / 4,6 / 5)$, que «disminuye o priva al hombre de su dignidad y derechos inalienables» (10/4).

El Evangelio del trabajo, por el contrario, da una visión humanista, «una imagen coherente, teológica y al mismo tiempo humanista del trabajo» $(13 / 2)$.

El pensamiento materialista y economicista «entendía el trabajo y lo trataba como una especie de «mercancía» que el trabajador - especialmente el obrero de la industria - vende al empresario, que a su vez es poseedor del capital»... o como una mercancía «sui generis», o como una fuerza anónima necesaria para la producción (se habla incluso de «fuerza-trabajo» $(7 / 2 ; 8 / 1,3$; 5/6; 9/4).

El economicismo materialista realiza «una inversión del orden establecido por Dios desde el comienzo con las palabras del libro del Génesis: el hombre es considerado como un instrumento de producción, mientras él -él solo, independientemente del trabajo que realiza - debería ser tratado como sujeto eficiente y su verdadero artífice y creador» (7/3). Comete de esta manera «una anomalía de gran alcance» que dio origen en el siglo pasado a la "cuestión proletaria» (8/2), que reaccionó contra «el sistema de injusticia y de daño, que pedía venganza al cielo, y que pesaba sobre el hombre del trabajo en aquel período de rápida industrialización» (8/3) y contra «sistemas ideológicos o de poder, así como nuevas relaciones surgidas a distintos niveles de la convivencia humana» que «han dejado perdurar injusticias flagrantes o han provocado otras nuevas» (8/4). Era «una situación favorecida por el sistema sociopolítico liberal que, según sus premisas de economicismo, reforzaba y aseguraba la iniciativa económica de los solos poseedores del capital, y no se preocupaba suficientemente de los derechos del hombre del trabajo, afirmando que el trabajo humano es solamente instrumento de producción y que el capital es el fundamento, el factor eficiente y el fin de la producción» $(8 / 3)$.

Tal error, que fue propio del capitalismo primitivo, «puede repetirse dondequiera que el hombre sea tratado de alguna manera a la par de todo el com- 
plejo de los medios materiales de producción, como instrumento y no según la verdadera dignidad de su trabajo, o sea como sujeto, autor y, por consiguiente, como verdadero fin de todo el proceso productivo» $(7 / 3)$, porque el peligro de la inversión de que estamos hablando «existe siempre, especialmente, cuando toda la visual de la problemática económica esté caracterizada por las premisas del economicismo materialista» $(7 / 2,3,4)$.

Para el Evangelio del trabajo todas esas incidencias económicas del trabajo, en las que queda atrapado el economicismo materialista, no pasan de ser como la periferia de la realidad laboral, porque «la Iglesia siempre ha expresado la convicción firme y profunda de que el trabajo no mira únicamente a la economía sino que implica además, y sobre todo, los valores personales» $(5 / 2)$. El Evangelio del trabajo, sin despreciar tales repercusiones económicas, necesita resquebrajarlas para llegar a la «misma característica interior que es la que constituye en cierto sentido la misma naturaleza del trabajo» (Introducción), para entrever «su misma esencia más profunda» $(4 / 2 ; 6 / 5 ; 13 / 2)$, aquello que «debe constituir el fundamento de las valoraciones y de las decisiones, que hoy se toman al respecto, incluso referidas a los derechos subjetivos del hombre, como atestiguan las Declaraciones internacionales y también los múltiples Códigos del trabajo, elaborados tanto por las competentes instituciones legisladoras de cada país, como por las organizaciones que dedican su actividad social o también científico-social a la prỏblemática del trabajo» (11/1); para verlo «desde el punto de vista del bien del hombre» procurando «hacer la vida más humana» $(3 / 2)$.

Tal «naturaleza o esencia profunda» se sitúa en «ser problema del hombre» (Introducción, $4 / 1 ; 10 / 1 ; 11 / 1 ; 1 / 2)$ que es su sujeto $(5 / 3,5$ etc.); en ser una dimensión fundamental de la existencia del hombre sobre la tierra $(4 / 2,3$; $8 / 1 ; 10 / 1 ; 11 / 6)$; en ser un bien no solamente «útil» o «para disfrutar» sino un bien «digno», es decir, que corresponde a la dignidad del hombre, un bien que expresa esta dignidad y la aumenta» $(9 / 3 ; 11 / 3)$, porque el trabajo es la realización de la «vocación» del hombre a dominar la tierra (Introducción; $6 / 2 ; 9 / 2 ; 10 / 4 ; 14 / 6$ etc.), porque «se desarrolla mediante su amor al trabajo» $(11 / 1)$ y encuentra en él «satisfacción personal y estímulo a la creatividad y responsabilidad» $(5 / 4)$.

También pertenece a su «naturaleza o esencia profunda» el «llevar en sí un signo particular del hombre y de su humanidad, como persona activa en medio de una comunidad de personas» (Introducción), que revela «toda la riqueza y a la vez toda la fatiga de la existencia humana sobre la tierra» (1/1) y que plantea «siempre nuevos interrogantes y problemas, nuevas esperanzas, nuevos temores y amenazas relacionadas con la vida del hombre» (1/2), como también «nuevos significados del trabajo humano» y «nuevos cometidos que 
en este campo se bijudan a cada hombre, a cada familia, a cada nación, a todo el género humano y, finalmente, a la misma Iglesia» $(2 / 1 ; 3 / 11 ; 5 / 3 ; 8 / 1)$. Por tanto es un signo que exige «una constante puesta al día» que sepa conservar «aquella base cristiana de verdad que podemos llamar perenne» $(3 / 1$ y se orienta en la dirección de «hacer la vida más humana» (3/2). Es una dimensión fundamental que «condiciona a su vez todo el proceso de educación» $(10 / 1)$, ya que el trabajo humano tiene un "carácter totalmente positivo y creativo, educativo y meritorio» (11/1).

Por todo ello el Evangelio del trabajo se esfuerza y apuesta en favor de cualquier iniciativa que procure conseguir que «las varias acciones pertenecientes al proceso del trabajo, independientemente de su contenido objetivo, sirvan todas ellas a la realización de su humanidad, al perfeccionamiento de esa vocación de persona, que tiene en virtud de su misma humanidad») (6/2; 6/6 etc.); apoya cualquier acción que se proponga conseguir que el trabajo, que ennoblece a la materia, no menoscabe la propia dignidad del hombre, no degrade al hombre «perjudicando sus fuerzas físicas - lo cual al menos hasta cierto punto es inevitable - y sobre todo menoscabando su propia dignidad y subjetividad» (9/4). Aplaude toda tesis que procure poner positivamente «el trabajo en función del hombre» y no al hombre «en función del trabajo» (6/6; $15 / 2 ; 21 / 3)$.

2. El economicismo-materialisita ha separado y contrapuesto el trabajo al capital «casi como dos fuerzas anónimas, dos factores de producción colocados juntos en la misma perspectiva «economicista» $(13,3,4)$; ha creado una «antinomia entre trabajo y capital... en cuyo marco el trabajo ha sido separado del capital y contrapuesto al mismo, en cierto sentido ónticamente como si fuera un elemento cualquiera del proceso económico...» (13/5).

La tesis propia del Evangelio del trabajo suena así: «La antinomia entre trabajo y capital no tiene su origen en la estructura del mismo proceso de producción, y ni siquiera en la del proceso ęconómico en general. Tal proceso demuestra en efecto la compenetración recíproca entre el trabajo y lo que estamos acostumbrados a llamar capital; demuestra su vinculación indisoluble» $(13 / 2)$.

La encíclica Laborem Exercens constata y admite con más nitidez que ningún otro documento magisterial la realidad de los hechos: Históricamente se ha desarrollado y está en curso un verdadero antagonismo entre el trabajo y el capital. No rehúye afrontar este problema en su misma raíz. A él dedica una de las cuatro partes (núms. 11-15) en que se divide la encíclica. Con sencillez y honradez evita cualquier expresión que pudiera interpretarse como «una connivencia con el «pseudo-pacifismo de cierta burguesía». El problema reviste tal importancia que le merece el calificativo de «gran conflicto» $(11 / 3)$, que 
comporta una verdadera explotación del hombre del trabajo en beneficio del capital $(11 / 3)$.

Es un hecho económico que no se agota en sí mismo, porque el conflicto socio-económico con carácter de clase se transforma en conflicto ideológico entre el liberalismo, entendido como ideología del capitalismo, y el marxismo, visto como ideología del socialismo científico (11/4). Finalmente el problema socio-económico - pasando por la ideologización que lo transforma en conflicto ideológico- se convierte en problema político puesto que el marxismo idolatra la «lucha de clases» como «la vía única para eliminar las injusticias, existentes en la sociedad, y las mismas clases sociales» (11/4). Tal lucha de clases ha de llevarse a cabo mediante determinados medios políticos como la dictadura del proletariado, el monopolio del poder por parte de la clase trabajadora y la supresión de la propiedad privada de los medios de producción con la implantación del sistema colectivista (11/5).

La Laborem Exercens sigue muy de cerca a las ideologías liberal y socialista en cuanto a los datos puramente descriptivos dęl conflicto trabajocapital: existencia e importancia del mismo. No así cuando se trata de la explicación, ideologizada y politizada, que una y otra ideología dan del conflicto, es la misma que se da entre unas ideologías que ignoran -consciente o inconscientemente - los valores éticos y aquella forma de pensar que sitúa los valores morales precisamente en el centro de su reflexión. La Laborem Exercens se sitúa por encima de ambas ideologías y subraya que una y otra sostienen orientaciones contrarias al recto orden del trabajo, es decir, al orden ético.

He aquí algunos elementos interpretativos divergentes:

a.- La encíclica, a diferencia de las ideologías, no examina las relaciones trabajo-capital ni las consecuencias del proceso económico, no las examina directamente desde la perspectiva económica, ni ideológica ni política, sino desde aquella perspectiva que le permite descubrir que todos «estos interrogantes encierran, una carga particular de contenidos y tensiones de carácter ético y ético social» $(11 / 5)$.

b.- Ni le satisfacen aquellas descripciones del problema que inclinan a pensar que en él no se juega nada de lo humano, como que las realidades que se enfrentan fueran puramente materiales sin relación alguna con el ser humano (13/3)... Tal concepción no la soporta el trabajo humano que es «una gran realidad, que ejerce un influjo fundamental sobre la formación, en sentido humano, del mundo dado al hombre por el creador y es una realidad estrechamente ligada al hombre como al propio sujeto y a su obrar racional» (11/1).

Por ello la Laborem Exercens experimenta una necesidad apremiante de 
traducir al lenguaje y significado ético las expresiones utilizadas, tanto por la mentalidad capitalista como por la comunista, para describir las fuerzas en conflicto: «mundo del trabajo» y «mundo del capital». La encíclica más que traducir plenifica tales expresiones resaltando su enorme contenido humano, viendo el problema «desde el punto de vista del hombre» (11/6), porque el mundo del trabajo y el del capital no son un mundo anónimo sino que está compuesto por hombres; es un conflicto «entre el grupo, restringido, pero muy influyente, de los empresarios, propietarios o poseedores de los medios de producción y la más vasta multitud de gente que no disponía de estos medios y que participaba en el proceso productivo exclusivamente mediante el trabajo» $(11 / 3 ; 13 / 1$; $14 / 1)$. Se impone, pues, una «imagen coherente teológica y al mismo tiempo humanista» (13/2), no puramente economicista o utilitarista, del conflicto porque quienes se enfrentan entre sí son sujetos humanos y también porque lo que resulta degradado en tal enfrentamiento es específicamente humano; la resultante degradada no es una fuerza productiva de tantas (13), ni un «elemento cualquiera del proceso económico» $(13 / 4)$, sino una realidad estrechamente ligada al hombre $(11 / 1)$, es el mismo hombre en el trabajo quien es degradado por otros hombres que actúan movidos por el pensamiento materialista del máximo beneficio $(11 / 3)$.

Como consecuencia de estas divergencias entre el pensamiento cristiano y esas ideologías, se ha de admitir que tales «contenidos y tensiones de carácter ético y ético-social» constituyen «un desafío continuo para múltiples iństituciones, para los Estados y para los gobiernos, para los sistemas y organizaciones internacionales; constituyen también un desafío para la Iglesia» $(11 / 5)$.

c.- Desde la perspectiva de los valores éticos «se ve claramente que no se puede separar el «capital» del «trabajo» y que de ningún modo se puede contraponer el trabajo al capital ni el capital al trabajo, ni menos aún - como se dirá más adelante- los hombres concretos, que están detrás de los conceptos, los unos a los otros» (13/1), porque tanto «el proceso éconómico como el proceso de producción: en general demuestran en efecto la compenetración recíproca entre el trabajo y lo que estamos habituados a llamar el capital; demuestran su vinculación inescindible» $(13 / 2)$. Tanto que el trabajo está llamado a ser el mejor medio de solidaridad y unión entre los hombres.

La Laborem Exercens defiende la convicción de que el enfrentamiento trabajo-capital no brota de la naturaleza de las cosas ni tampoco de la naturaleza de la actividad económica en general ni del proceso producti- 
vo en concreto (13/2), sino que solamente el hombre es responsable -al violentar la naturaleza de las cosas - de la ruptura de «esta imagen coherente» de la compenetración trabajo-capital (13/3; 7/7); es el hombre quien ha introducido la subversión del orden justo que crea tensiones en cada nación y en las relaciones Este-Oeste y, sobre todo, Norte-Sur» $(7 / 4)$.

Se trata de una ruptura introducida primeramente «en la vida práctica», a consecuencia del error economicista-materialista, y que, posteriormente lo teorizó, como buscando justificar la práctica mediante las correspondientes formulaciones teóricas (13/). Y ninguno de los sistemas actuales está libre de esta mentalidad. Tienen mucho que ver los «sistemas ideológicos de poder, como también las nuevas relaciones nacidas a nivel de vivencia humana» que «han dejado perdurar injusticias flagrantes o han provocado otras nuevas» $(8 / 4)$.

No faltan autores convencidos de que la Laborem Exercens adjudica, en estos pasajes, al capitalismo mayor responsabilidad negativa que al comunismo en la inversión de los valores. Otros, en cambio, consideran que tal interpretación fuerza no solamente la letra sino también el texto de pasajes concretos y también el contexto de los lugares paralelos. Es cierto que Juan Pablo II afirma que el materialismo teórico ha ido precedido por el materialismo práctico $(13 / 4)$, pero se trata simplemente de una prioridad temporal y no ontológica. Obviamente la reacción comunista se ha verificado después, pero produciendo una esclavitud y una tiranía cruel, mucho peor que el mal que se quería extirpar, como lo confirma la triste experiencia actual. De hecho el Papa añade inmediatamente: «También en el materialismo dialéctico el hombre no es ante todo sujeto del trabajo y causa eficiente del proceso de producción, sino que es entendido y tratado como dependiendo de lo que es material, como una especie de «resultante» de las relaciones económicas y de producción predominantes en una determinada época» (13/4).

3. En el economicismo-materialista «el trabajo humano es solamente instrumento de producción y el capital es el fundamento, el factor eficiente y el fin de la producción» (8/3); «...el materialismo incluye, directa o indirectamente, la convicción de la primacía y de la superioridad de lo que es material, mientras por otra parte el economicismo sitúa lo que es espiritual y personal (la acción del hombre, los valores morales y similares) directa o indirectamente, en una posición subordinada a la realidad material».(13/3). Y «también en el materialismo dialéctico el homure no es ante todo sujeto del trabajo y causa eficiente del proceso de producción, sino que es entendido y tratado como dependiendo de lo que es material, como una especie de «resultante» de las rela- 
ciones económicas y de producción predominantes en una determinada época» $(13 / 4)$.

El Evangelio del trabajo gira en torno a la tesis de que el capital es para el hombre, no el hombre para el capital.

La mutua relación de inseparabilidad trabajo-capital se especifica más: Esa inseparabilidad es matizada por la superioridad del trabajo sobre el capital. El trabajo necesita que el capital se le someta a su servicio como el objeto al hombre, como el instrumento a la causa eficiente. Subordinación que no implica deprecio alguno del capital. Lo valora, y muy positivamente, pero en una relación de subordinación que precisa y adjetiva con estos términos: «del capital solamente podemos afirmar que condiciona el trabajo del hombre; no podemos, en cambio, afirmar que ello constituya casi el «sujeto» anónimo que hace dependiente al hombre y su trabajo» (13/2), de manera que «intrínsecamente verdadero y moralmente legítimo, puede ser aquel sistema de trabajo que en su raíz supera la antinomia entre trabajo y capital, tratando de estructurarse según el principio expuesto más arriba de la sustancial y efectiva prioridad del trabajo, de la subjetividad del trabajo humano y de su participación eficiente en todo el proceso de producción, y eso independientemente de la naturaleza de las prestaciones realizadas por el trabajador» (13/1).

Para llegar a estas afirmaciones Juan Pablo II se sitúa, una vez más, a nivel filosófico y' humano.

a.- Dependencia ontológica final del capital en relación con el trabajo. Solo el hombre es persona, mientras que el capital lo componen cosas.

El hombre, como sujeto del trabajo e independientemente del trabajo que realice «el hombre, él solo, es una persona. Esta verdad contiene en sí consecuencias importantes y decisivas» (12/6. 6/2,3,6; 13/1).

El trabajo participa de la dignidad de la persona sobre las cosas ya que «el fundamento para determinar el valor del trabajo humano no es en primer lugar el tipo de trabajo que realiza, sino el hecho de que quien lo realiza es una persona» (6/5); «el fundamento del valor del trabajo es el hombre mismo, su sujeto» (6/6). De manera que el valor ético del trabajo, del cual no cabe la menor duda «está vinculado completa y directamente al hecho de quien lo lleva a cabo es una persona, un sujeto consciente y libre, es decir, un sujeto que decide de sí mismo» $(6 / 2,3)$.

Mientras que el capital son cosas: «Conviene subrayar y poner de relieve la primacía del hombre respecto a las cosas. Todo lo que está contenido en el concepto de «capital» -en sentido restringido- es solamente un conjunto de cosas» (12/6). Para el Evangelio del trabajo un principio «enseñado siempre por la Iglesia es el principio de la prioridad del trabajo sobre el capital» $(12 / 1)$. Se trata de una prioridad sustancial $(13 / 1)$ 
hasta el punto de que «si en el proceso del trabajo se descubre alguna dependencia, ésta es la dependencia del Dador de todos los recursos de la creación, y es a su vez la dependencia de los demás hombres, a cuyo trabajo y a cuyas iniciativas debemos las ya perfeccionadas y ampliadas posibilidades de nuestro trabajo» (13/2); siendo el hombre «el señor» de las criaturas que están puestas a su disposición en el mundo visible» $(13 / 2)$. Es éste un pensamiento frecuentemente repetido en la encíclica $(12 / 4)$.

b.- Dependencia instrumental: Solo el hombre es sujeto; el capital es instrumento. El trabajo «condiciona» al hombre, pero «no podemos, en cambio, afirmar que ello constituya casi el «sujeto» anónimo que hace dependiente al hombre y su trabajo» $(13 / 2 ; 6 / 2)$.

El hombre, «él solo, independientemente del trabajo que realiza, debería ser tratado como sujeto eficiente y su verdadero artífice y creador» $(7 / 3 ; 12 / 5 ; 5 / 3)$, de manera que sean cuales fueren las transformaciones del proceso objetivo del trabajo y del proceso industrial, llegando el hombre a limitarse solamente a vigilar a la máquina, siempre será el hombre y seguirá siendo el sujeto del trabajo (5/3).

c.- Dependencia de origen: El hombre es el sujeto, la causa eficiente; el capital es el producto del trabajo del hombre.

El conjunto de medios con los cuales el hombre se apropia de los recursos puestos por la naturaleza a disposición del hombre, transformándolos según sus necesidades (12/4), «el conjunto de medios de producción, que son considerados, en un cierto sentido como sinónimo de capital» $(12 / 5)$ es fruto del patrimonio histórico del trabajo humano $(12 / 4)$, es el producto del trabajo de generaciones» (14/4), y llevan consigo las señales del trabajo humano (12/5). «Todos los medios de producción, desde los más primitivos hasta los ultramodernos, han sido elaborados gradualmente por el hombre: por la experiencia y la inteligencia del hombre. De este modo, han surgido no sólo los instrumentos más sencillos que sirven para el cultivo de la tierra, sino también - con un progreso adecuado de la ciencia y de la técnica- los más modernos y complejos: las máquinas, las fábricas, los laboratorios y las computadoras. Así, todo lo que sirve al trabajo, todo lo que constituye - en el estado actual de la técnica - su «instrumento cada vez más perfeccionado, es fruto del trabajo» (12/4).

4. El economicismo materialista sitúa el valor del trabajo en su dimensión objetiva, mientras que el Evangelio del trabajo lo radica en su aspecto subjetivo, respondiendo así al «esfuerzo a través del cual la enseñanza de la iglesia acerca de la propiedad ha tratado y sigue tratando de asegurar la primacía del 
trabajo, y por lo mismo, de la subjetividad del hombre en la vida social, especialmente en la estructura dinámica de todo el proceso económico» $(14 / 4,7)$.

En «la civilización unilateralmente materialista se da importancia primordial a la dimensión objetiva del trabajo, mientras la subjetiva - todo lo que se refiere indirecta o directamente al sujeto del trabajo - permanece a un nivel secundario» $(7 / 3,4)$; de manera que el trabajador no tiene otra salida que «poner su trabajo a disposición del grupo de los empresarios» y soportar que dicho grupo someta el trabajo al «principio del máximo rendimiento» por lo que establecen «el salario más bajo posible para el trabajo realizado por los obreros» (7/3), conduciendo a la «degradación del hombre como sujeto del trabajo» y a una «inaudita y concomitante explotación en el campo de las ganancias, de las condiciones de trabajo y de previdencia hacia la persona del trabajador» $(8 / 3)$.

La civilización unilateralmente materialista no acierta a ver la cuestión social ni el trabajo desde «el bien del hombre» $(3 / 2)$, pierde de vista el fin o sea el hombre, al cual deben servir estos medios» (13/5). Tal civilización queda prisionera de la consideración del trabajc «como una especie de mercancía, como una fuerza necesaria para la producción o fuerza-trabajo, a lo más como una mercancía sui generis», que el trabajador -especialmente el obrero de la industria - vende al empresario (7/2), lo cual le obliga a relegar «a un nivel secundario la dimensión subjetiva, del trabajo, es decir, todo lo que se refiere indirecta o directamente al mismo sujeto del trabajo» $(7 / 3)$.

La mentalidad unilateralmente materialista no descubre más que el trabajo-actividad. Lo considera solamente en cuanto que esa actividad "está dirigida hacia un objeto externo», exclusivamente como actividad «transitiva» y por tanto desde la impronta que deja en el objeto trabajado, producto elaborado, ignorando que también es, $\mathrm{y}$ ante todo, una actividad inmanente que comienza en el sujeto y se finaliza principalmente en el mismo sujeto $(4 / 3)$. Lo ve únicamente en cuanto que el trabajo crea prugreso en la ciencia, en la técnica y descubrimientos decisivos para la vida socioeconómica (4/4). Ve el trabajo como un proceso material mediante el cual el hombre y el género humano someten también materialmente la tierra... olvidando que en él el hombre se manifiesta y confirma como el que domina (6/3); predomina el valor objetivo más o menos importante del trabajo, concediendo significado definitivo por sí mismo a la finalidad objetiva que tenga el trabajo (6/6). Y si el trabajo posee valor definitivo por sí mismo, todos los demás elementos integrantes del trabajo son valorados en relación con ese significado objetivo del mismo. De ahí que se le considere como una mercancía $(7 / 2)$ y que sea «tratado a la par de todo el complejo de los medios materiales de producción, como instrumento de producción y no según la verdadera dignidad de su trabajo» 
(7/3); ur instrumento que se ve sometido al agobio de la máquina que tiende a despersonalizarlo $(8 / 2)$, y crea la contradicción de que el trabajo que ennoblece a la materia, degrada a la dignidad y subjetividad del hombre $(9 / 4)$.

Consecuencia lógica es la diversidad de expresiones que recibe el trabajo según «las épocas de la cultura y de la civilización» $(5 / 1 ; 8 / 1)$, y que conduce a la división entre los hombres, como lo atestigua la edad antigua que introdujo entre los hombres una propia y típica diferenciación según el tipo de trabajo que realizaban $(6 / 5)$.

La Laborem Exercens, asentado el primado del trabajo sobre el capital, concreta cuidadosamente el aspecto del trabajo del que brota esta superioridad, que no es otro que su dimensión subjetiva como condicionante de la esencia ética del trabajo (6/3).

Para ello Juan Pablo II comienza por ofrecernos un concepto inusual del trabajo, como dice Buttiglione, y también la distinción de esa doble dimensión del trabajo: su dimensión objetiva y la subjetiva.

La Laborem Exercens abandona ciertas concepciones del trabajo: la pecaminosa, por ejemplo, que venía a considerarlo, más o menos directamente, como un castigo que Dios hubiera impuesto al hombre por su pecado y que el hombre debiera santificar mediante sus actitudes personales. Lejos de tal concepción el trabajo es una dimensión fundamental del ser humano, distintiva de cualquier otra criatura no racional y con un valor tal en sí mismo que le permite hablar del Evangelio del trabajo. De hecho la Laborem Exercens presenta el trabajo como vocación del hombre, como relación comunicativa, como solidaridad, como creador de cultura, como participación.en la obra creadora de Dios y con referencia constante a Cristo, primer Evangelio del trabajo.

Otro tanto ocurre con la concepción instrumentalizadora del trabajo que lo considera casi exclusivamente como la actividad con la que el hombre se procura los medios de subsistencia. La Laborem Exercens nos presenta una concepción 'del trabajo articulada en sus finalidades, en su dimensión personal y social y en su valor religioso. De aquí que trabajo es toda actividad con la que el hombre contribuye a mejorar la calidad de vida y al progreso de la cultura. Comprende, por tanto, no solamente el trabajo manual -agrícola, industrial o doméstico - sino también el trabajo de las profesiones liberales, de la investigación científica y de la actividad política $(9 / 2)$.

Trabajo significa todo tipo de acción realizada por el hombre independientemente de sus características o circunstancias (Introducción)..., en cuanto que se convierte en una «característica que distingue al hombre del resto de las criaturas» (introducción), puesto que «constituye el contexto en el que se inueve el hombre» (1/1) y es uno de los aspectos en los que se desvela toda la 
riqueza y a la vez toda la fatiga de la existencia humana sobre la tierra (1/1).

$\mathrm{El}$ aspecto o dimensión subjetiva del trabajo es la que encuentra un desarrollo mayor, y hasta absorbente, en la encíclica (6/1). Todos los demás aspectos del trabajo, incluso su dimensión objetiva, quedan en segundo plano. En tanto se ocupa de ellos en cuanto que ello sirva para delimitar y subrayar el primado de la dimensión subjetiva del trabajo sobre cualquiera de los otros aspectos del mismo (5/6).

Creo que la Laborem Exercens presenta una doble acepción de la dimensión subjetiva del trabajo. Hay elementos que pertenecen diréctamente a tal dimensión, mientras que otros entran solo indirectamente a formar parte de la misma. El fundamento de esta distinción nos lo da la Introducción: «Con su trabajo el hombre ha de procurarse el pan cotidiano, contribuir al continuo progreso de las ciencias y la técnica, y, sobre todo, a la incesante elevación cultural y moral de la sociedad en la que vive en comunidad con sus hermanos».

Directamente pertenece a la dimensión subjetiva del trabajo toda y sola «la realidad concreta del hombre del trabajo» $(10 / 6 ; 6 / 1,3)$; cuanto puede encuadrarse dentro del término «subjetividad» (13/1), o «todo lo que se refiere directa o indirectamente al mismo sujeto del trabajo» (7/3). La dimensión subjetiva directa del trabajo hace referencia al trabajo en cuanto que es una actividad del hombre (4/2), en cuanto que es acto de una persona humana $(8 / 1 ; 24 / 1)$, en cuanto que el trabajo, como actividad transitiva, encuentra su origen en el hombre $(4 / 3 ; 6 / 6)$ y como tal el trabajo es «una actividad consciente del hombre por la que descubre y usa oportunamente las cosas» (4/3); en cuanto que mediante el trabajo el hombre realiza su propia capacidad de someter la tierra $(4 / 2)$ y se confirma como dueño y dominador de lo creado $(5 / 1 ; 4 / 3 ; 9 / 1,2$; en cuanto que todas las acciones con que el hombre participa en el proceso de producción «independientemente de su contenido objetivo han de servir a la realización de su humanidad» $(6 / 2)$ y es un bien del hombre $(9 / 3,4 ; 11 / 1)$.

La dimensión subjetiva del trabajo, es decir, la realidad concreta del hombre del trabajo «que consiste en el dar posibilidad de desarrollar tres ámbitos de permanente importancia para el trabajo humano en su dimensión subjetiva» (10/4): personal, familiar $(10 / 1)$ y nacional $(10 / 3 ; 11 / 1,12 / 4)$. También lo explicita con otra fórmula que relaciona el trabajo con el cultivo de los «derechos del hombre en su sentido más amplio» (14/6) o con los «derechos fundamentales del hombre» $(14 / 1,7)$ o con «los justos derechos de los hombres del trabajo» (20/6).

Indirectamente integran la dimensión subjetiva del trabajo todos sus elementos, incluso su aspecto objetivo, en cuanto que es considerado «desde el punto de vista del hombre» $(11 / 6)$, desde la «fundamental dimensión de su su- 
jeto» $(8 / 1)$, lo cual convierte todo el proceso de producción, su dimensión objetiva, en signo y sacramento de lo que es el hombre: «el que domina» (6/3) y consigue que «independientemente del trabajo que el hombre realiza, y suponiendo que ello constituye su finalidad - a veces muy exigente- de su obrar, esta finalidad no posee un significado por sí mismo. De hecho, en fin de cuentas, la finalidad del trabajo, de cualquier trabajo realizado por el hombre -aunque fuera el trabajo «más corriente», más monótono, en la escala del modo común de valorar, e incluso el que más margina- permanece siempre el hombre mismo» $(6 / 5)$.

La dimensión objetiva del trabajo es aquella que obtenemos cuando lo consideramos no desde su vertiente inmanentista, sino en cuanto actividad «transitiva» que el hombre desarrolla en el mundo, "dirigida hacia un objeto externo» (4/3); lo es todo el proceso del trabajo contemplado en aquello que el hombre incorpora a las cosas dominándolas $(5 / 1)$, transformándolas y adaptándolas a las necesidades humanas $(9 / 3 ; 12 / 2)$, creando la técnica $(10 / 4$; $4 / 3 ; 5 / 1)$. La dimensión objetiva del trabajo se identifica con el efecto que aquél produce en las cosas (4/3), los frutos del trabajo, considerados en su dimensión económica $(5 / 5 ; 13 / 3)$. Ello conduce a la consideración del trabajo como mera mercancía $(7 / 2 ; 7 / 2 ; 6 / 5,11 / 3)$.

El Evangelio del trabajo parte de la convicción de que «no hay duda de que el trabajo tiene un valor ético el cual está vinculado completa y directamente al hecho de quien lo lleva a cabo es una persona, un sujeto consciente y libre, es decir, un sujeto que decide por sí mismo» (6/3). Tal vinculación del valor ético del trabajo a la dignidad de la persona la enuncia con ligeras variantes en repetidas ocasiones: «el fundamento para determinar el valor del trabajo no es en primer lugar el tipo de trabajo que realiza, sino el que quien lo realiza en una persona» (6/4); «quiere decir que el primer fundamento del trabajo es el hombre mismo, su sujeto»; con lo que «queremos poner en evidencia» que «suponiendo que algunos trabajos realizados por los hombres pueden tener un valor objetivo más o menos grande, sin embargo cada uno de ellos se mide sobre todo con el metro de la dignidad del sujeto mismo del trabajo, o sea de la persona, del hombre que lo realiza» (6/6).

Lógicamente concluye asegurando que la dimensión subjetiva «condiciona la esencia misma del trabajo» (6/3); que las fuentes del valor ético o dignidad del trabajo «deben buscarse no en su dimensión objetiva, sino en su dimensión subjetiva» (6/5); llegando «justamente a reconocer la preeminencia del significado subjetivo del trabajo sobre el significado objetivo» (6/6); o de otra forma «la dimensión subjetiva, es decir, la realidad concreta del hombre del trabajo, tiene precedencia sobre la dimensión objetiva» $(10 / 4)$ puesto que 
el dominio que el hombre ejerce sobre las cosas «en cierto sentido se refiere más a la dimensión subjetiva que a la objetiva» $(6 / 5 ; 10 / 4)$.

De la fuerza vinculante del primado de la dimensión subjetiva del trabajo se desprenden algunas conclusiones que la encíclica hace notar. Entre otras: el enorme progreso de los medios de producción «es un fenómeno ventajoso y positivo, a condición de que la dimensión objetiva del trabajo no prevalezca sobre la dimensión subjetiva, quitando al hombre o disminuyendo su dignidad y sus derechos inalienables» (10/4); un sistema social será «justo, es decir, conforme a la esencia misma del problema; justo, es decir, intrínsecamente verdadero y a su vez moralmente legítimo, puede ser aquel sistema de trabajo que en su raíz supera la antinomia entre trabajo y el capital, tratando de estructurarse según el principio expresado más arriba de la sustancial y efectiva prioridad del trabajo, de la subjetividad del trabajo humano y de su participación eficiente en todo el proceso de producción, y esto independientemente de la naturaleza de las prestaciones realizadas por el trabajador» (13/1); también influye, el primado de la dimensión subjetiva del trabajo, en la orientación que debe darse a la propiedad $(14 / 4,3,6)$, de los sindicatos $(20 / 6)$, de la agricultura $(21 / 1)$, del trabajo de los minusválidos $(22 / 1$ y 3$)$ y de los convenios internacionales sobre el trabajo $(18 / 3 ; 7 / 4)$.

\section{JUICIO SIMÉTRICO DE CAPITALISMO Y COMUNISMO}

La ciencia económica ha superado ya la etapa que acentuaba las diferencias singularizadoras de cada uno de los grandes sistemas económicos. Hoy gira en torno a la teoría de la convergencia de los sistemas ${ }^{7}$. Otro tanto está ocurriendo en el ámbito de la reflexión ética sobre los citados sistemas económicos, si bien fundamentándose en razones específicas del pensamiento éticosocial. La ética, desde su punto específico de vista, más que defender una convergencia entre los sistemas, apuesta por una superación de los mismos que se realizará progresivamente al ritmo con que el trabajo, el hombre del trabajo, logre imponer su primado sobre el capital y sobre los medios de producción ${ }^{8}$.

Juan Pablo II no se detiene ni en el análisis pormenorizado de uno $\mathrm{u}$ otro

7. G. SCIDA, «La teoria della convergenza tra sistemi sociali differenti»: Aggiornamenti Sociali 31 (1980) 173-9; I. CAMACHO, «El socialismo en la Laborem Exercens»: en AA.VV., Juan Pablo II y la justicia social, Razón y Fe, Madrid 1982, 54.

8. CAMACHO, I., «Laborem Exercens: ¿Qué sistema económico? Proyección 29 (1982/126) 210; UNCITI, M., «Primera aproximación a la encíclica»: Iglesia Viva (1982/97-98) 8-9. 
sistema, ni en subrayar sus diferencias, sino en su opción fundamental, común a ambos sistemas e incompatible con la visión cristiana, opción economicista materialista ${ }^{9}$. Tales premisas conducen a la encíclica a pronunciar un juicio común y único sobre los dos sistemas: capitalismo y socialismo. Es lo que los comentaristas denominan «juicio o tratamiento simétrico» de ambos sistemas. De esta manera la consideración unificada de ambos sistemas deja de ser la opinión particular de uno u otro pensador, para convertirse, por la autoridad de la Laborem Exercens, en la tesis que el Magisterio propone oficialmente a toda la comunidad cristiana. Esta encíclica pone fin al tratamiento asimétrico de los sistemas económicos, que venía siendo una constante en el pensamiento ético-social y que consideraba al capitalismo lícito en sí mismo, aunque duramente censurable en sus realizaciones históricas, mientras el comunismo era condenado como radicalmente ilícito en sí mismo.

Algunos autores señalan este cambio como «la principal novedad de la encíclica» ${ }^{10}$, tanto tiempo esperada por estudiosos católicos y sobre la que Alberdi escribía: «...tenemos la convicción de que la Iglesia hablará con más claridad aún acerca del capitalismo actual. Habrá que esperar a la maduración de la conciencia del Pueblo de Dios, in capite et in membris. Esta maduración es inseparable de un conocimiento más exacto de la esencia y las verdaderas relaciones del capitalismo» ${ }^{11}$. Y comenta J.M. Osés: «En la encíclica Laborem Exercens vemos realizada la lógica afirmación de Alberdi; digo lógica porque, siendo patente para muchos la incompatibilidad del capitalismo con una visión cristiana no ideologizada por el mismo sistema, sentíamos un cierto malestar ante la falta de rechazo sin paliativos del capitalismo; tanto más necesaria era una toma de postura cuanto mayor era la inconsciencia - cuando no muy alertada e interesada conciencia - sobre la radicalidad negativa del capitalismo; inconsciencia alimentada por la imprecisión del Magisterio en la valoración del capitalismo. Esta clarificación se hacía sentir más aún por la rotundidez con que históricamente la Iglesia había rechazado el comunismo y que tan hondo había calado en los católicos.

«En esto radica una de las causas que explican un hecho contradictorio: mientras hay personas que se consideran y dicen ser cristianos y que, por eso

9. ReinA, M., «Per una introduzione alla enciclica Laborem Exercens»: Aggiornamenti Sociali 32 (1981) 662-663; CAMACHO, I., «El socialismo en la Laborem Exercens»: en Juan Pablo II y la justicia social; Razón y Fe, Madrid 1982, 54-55; AA.VV., Il lavoro per l'uomo, Città Nuova Editrice, Roma 1982, 11, 50; BELDA, R., "¿Cuál es la principal aportación doctrinal de la encíclica Laborem Exercens?»: Iglesia Viva (1982/97-98) 18-19; VELASCO, D., «Reflexión crítica sobre el socialismo real»: Iglesia Viva (1982/97-98) 59ss.

10. CAMACho, I., «El socialismo en la Laborem Exercens»: en AA.VV., Juan Pablo II y la justicia social, Razón y Fe, Madrid 1982, 47.

11. AleERDI, R., «Juicio cristiano sobre el capitalismo»: Iglesia Viva, n. 10-11 (1967)·352. 
mismo, se escandalizan cuando oyen que algunos cristianos son comunistas, no sufren escándalo alguno ante cristianos que se dicen $-\mathrm{y}$ son- capitalistas» ${ }^{12}$.

\section{A) Abandono de la concepción histórica del capitalismo}

La experiencia personal de Juan Pablo II y la convicción de lo infundado que es contraponer rígidamente el capitalismo al socialismo han abierto la posibilidad a este juicio o tratamiento simétrico de ambos sistemas ${ }^{13}$. No es acertado contraponer las ideologías de ambos sistemas y presentar a la ideología liberal como aquella que considera el trabajo como un puro factor de producción, subordinado al capital, como una mercancía y, por tanto, dirigido por la ley de la oferta y la demanda y afirmar que la ideología marxista coloca el trabajo en el centro y, mediante la lucha de clases, se proponé liberarlo de la alienación en que lo ha hundido el capitalismo. Ni es tampoco acertado contraponerlas por las tesis opuestas que defienden en el tema de la propiedad privada ${ }^{14}$.

La Laborem Exercens nos previene contra el peligro de circunscribir la esencia del capitalismo a sólo el sistema capitalista. El espíritu capitalista puede inspirar también y convertirse en la columna vertebral de otros sistemas, aunque históricamente tales sistemas hayan luchado encarnizadamente contra el capitalismo. Por eso la Laborem Exercens olvida intencionadamente el contorno histórico en el que se han contrapuesto y desarrollado capitalismo y socialismo y prefiere penetrar un poco más «en la realidad fundamental de todo el proceso económico y de las estructuras de producción» ${ }^{15}$. Desde esta perspectiva concluye que la esencia del capitalismo consiste en despojar al trabajo de su dimensión, valor y dignidad humanas y tratarlo como un elemento material integrante del sistema de producción ${ }^{16}$, como una mercancía o como una fuerza necesaria del sistema de producción, como un instrumento y no como sujeto, autor y, por lo tanto, como verdadero fin de todo el proceso pro-

12. OsÉs, J.M., «Reflexion sobre el capitalismo»: Iglesia Viva 1982/97-98) 45; GARCíA M., «Hay alternativas al capitalismo y al colectivismo?»: Sal Terrae 70 (1982) 45-53.

13. M. ANTOLI, «Reflexiones en torno a la Laborem Exercens»: Anales Yalentinos 8 (1982) 211; СамACHO, I., a.c., 50.

14. MatTaI, G., Lettera enciclica Laborem Exercens di Giovanni Paolo II, Paoline, Roma 1981, 14-15.

15. Laborem Exercens 7/2, 3; SPIAZZI, R., L'enciclica sul lavoro: Laborem Exercens, Massimo, Milano 1981, 27-28.

16. Laborem Exercens, 7/3; OsÉs, J.M., «Reflexión crítica sobre el capitalismo»: Iglesia Viva (1982/97-98) 59-60. 
ductivo. Y esto se da no solamente en el capitalismo, sino que el error, que originariamente cometió el primitivo capitalismo, «puede repetirse en cualquier sistema» y concretamente se repetirá en cualquier sistema cuya concepción esté caracterizado por las premisas del economicismo materialista, porque «tales situaciones independientemente de la denominación del sistema que las produzca, merece el nombre de capitalismo» ${ }^{17}$.

\section{B. Juicio simétrico de ambos sistemas}

Creo que podemos admitir que la Laborem Exercens considera los sistemas económicos desde dos ángulos. Por una parte los contempla desde la ideología que informa a cada uno de los sistemas y por la otra los somete a examen en cuanto movimientos que se han desarrollado históricamente con unas determinadas estructuras.

La distinción entre ideología y movimiento se ha hecho común a partir de la Pacem in Terris. Juan XXIII nos recuerda que «se ha de distinguir cuidadosamente entre las teorías filosóficas sobre la naturaleza, el origen, el fin del mundo y del hombre, y las iniciativas de orden económico, social, cultural o político, por más que tales iniciativas hayan sido originadas e inspiradas en tales teorías filosóficas...» ${ }^{18}$.

En el párrafo citado nos ha ofrecido como una delimitación de contenido entre ideología y movimiento.

Las ideologías son:

- falsas doctrinas filosóficas sobre la naturaleza, el origen y el destino del universo y del hombre;

- que se erigen como nuevos dioses que quieren desbancar a Dios... presentándose como la explicación última y suficiente de todo, como justi.. ficación de la propia acción, aún violenta y concretamente dice que la ideología marxista «pretende ofrecer una visión total y autónoma del hombre»;

- que tienen un carácter totalitario y coercitivo hasta el punto que «a veces llegan a reducir la acción política y social a ser una simple aplicación de una ideología abstracta, puramente teórica; y a veces el pensamiento se convierte en un puro instrumento al servicio de la acción, como un simple medio de una estrategia. En ambos casos, ¿no es el hombre quien corre el riesgo de verse alienado?;

- finalmente, «las doctrinas, una vez elaboradas y definidas, ya no cam-

17. Laborem Exercens, 7/2, 3 .

18. Pacem in Terris, n. 159. 
bian, mientras que tales iniciativas, encontrándose en situaciones históricas continuamente variables, están forzosamente sujetas a los mismos cambios» ${ }^{19}$.

Por todo ello las ideologías, así entendidas, son incompatibles con la fe cristiana: «El cristiano que quiere vivir su fe en una acción política, concebida como servicio, tampoco puede adherirse sin contradicción a sistemas ideológicos que se oponen radicalmente, o en puntos sustanciales, a su fe y a su concepción del hombre: ni a la ideología marxista, a su materialismo ateo, a su dialéctica de violencia y a la manera como ella entiende la libertad individual dentro de la colectividad, negando al mismo tiempo toda trascendencia al hombre y a su historia personal y colectiva; ni a la ideología liberal que cree exaltar la libertad individual, sustrayéndola a toda limitación, estimulándola con la búsqueda exclusiva del interés y del poder, y considerando las solidaridades sociales como consecuencia más o menos automática de iniciativas individuales, y no como un fin y un criterio más elevado del valor de la organización social» ${ }^{20}$.

Los sistemas económicos, como movimientos que se han desarrollado históricamente, son enjuiciados en la tercera parte de la encíclica. Se advierte que nunca los denomina con la terminología habitual, capitalismo socialismo, sino que los describe y enjuicia desde las actitudes que toman frente al hombre, que, por lo demás son comunes a uno y otro sistema. La encíclica se sitúa así por encima de las discusiones ideológicas que oponen a los defensores de uno y otro sistema, porque Juan Pablo II no intenta defender a ninguno de los dos sistemas, sino que pretende orientar los actuales, y también los posibles futuros sistemas, al servicio del hombre, de todos y cada uno de los hombres ${ }^{21}$.

La Laborem Exercens repite con frecuencia los términos economicismo y materialismo para designar la inversión del justo orden de valores, que forman el denominado Evangelio del trabajo ${ }^{22}$.

El economicismo establece como fin propio del proceso productivo «multiplicar grandemente las riquezas materiales» ${ }^{23}$. Da origen a un sistema que en tanto aprecia el trabajo en cuanto que contribuye aficazmente al aumento de

19. Pacem in Terris, n. 159; Octogessima Adveniens, n. 26-29.

20. Octogessima Adveniens, n. 26.

21. GATTI, G., «Il lavoro umano. Guida a una lettura dell'enciclica Laborem Exercens di Giovanni Paolo II»: Catechesi (1982/9) 38.

22. CAMAcho, I., «Desde dónde leer la Laborem Exercens»: Proyección 29 (1982) 126; REINA, M., «Per una introduzione alla enciclica Laborem Exercens»: Aggiornamenti Sociali (1981) 658; Laborem Exercens, n. 7/3, 1/3.

23. Laborem Exercens, n. 13. 
la producción y no valora su significación humana y personal ni su aportación al desarrollo de la persona que lo realiza, para terminar sometiendo el trabajo al capital ${ }^{24}$. El economicismo valora según los costes en dinero tanto al trabajo como a las materias primas y tecnología. Su interés es que tanto el trabajo como los medios de producción sean lo menos costosos posible y la producción óptima. La decisión sobre todos estos elementos se la reserva el capital. Su poder es absoluto. El único principio que no admite discusión es el de la rentabilidad del dinero. Para que la empresa funcione ha de producir beneficios. El dueño del capital decidirá sobre la continuidad o no de la empresa, mientras que el trabajo, el trabajador, deberá conformarse con un salario un poco mejor en períodos prósperos y con el simple conservar su puesto de trabajo en períodos de crisis. Al econocimismo le interesa más la calidad y cantidad de lo producido que el sujeto que lo produce, que en realidad no es considerado nada más que en función de lo que produce ${ }^{25}$.

El economicismo desemboca en el materialismo. Éste defiende el primado y superioridad de lo material sobre lo espiritual, que es considerado como un fenómeno superfluo ${ }^{26}$. Abriga la pretensión de apagar los deseos del hombre, confiándose en la atracción que ejerce lo material ${ }^{27}$. El dar más importancia a la dimensión objetiva y material del trabajo que a su dimensión subjetiva o personal también hunde sus raíces en este materialismo ${ }^{28}$.

En ambos sistemas domina el materialismo, cuyo nacimiento ha ido unido históricamente a la ideología liberal y al capitalismo, pero posteriormente extendió su radio de acción al sistema comunista, reforzándose como materialismo dialéctico ${ }^{29}$.

El capitalismo es denunciado, en varias ocasiones, como un materialismo no teórico pero sí práctico ${ }^{30}$. Como si la encíclica quisiera clarificar la verda-

24. Laborem Exercens, n. 8; Schasching, J., «L'uomo e il lavoro. Dalla «Rerum Novarum» alla Laborem Exercens»: Rassegna di Tęologia 23 (1982) 4.

25. Laborem Exercens, n. 13/3; 7/3; 11/3; CAMACHO, I., a.c., p. 50; Molinaro, A., «conflitti umani nel lavoro» en AA.VV., Il lavoro per l'uomo, Città Nuova Editrice, Roma 1982, 5051; TALIERCIO G., «Il diritto di proprietà nella Laborem Exercens»: Palestra del Clero 61 (1982) 1230; CAMACHO, I., «Laborem Exercens: ¿Qué sistema económico?»: Proyección 29 (1982) 200.

26. Laborem Exercens, n. 13/3, 4; 7/3; 6/2; BIFFI, F., «Le grandi linee dell'enciclica»: en AA.VV., Il lavoro per l'uomo, Città Nuova Editrice, Roma 1982, 11-12; BELDA, R., «¿Cuál es la principal aportación doctrinal de la encíclica Laborem Exercens?»: Iglesia Viva (1982/97-98) 20; OsÉs, J.M., «Reflexión crítica sobre el capitalismo»: Iglesia Viva (1982/97-98) 50; VELASCO, D., «Reflexión crítica sobre el socialismo real»: Iglesia Viva (1982/97-98) 73; AA.VV., Laborem Exercens. L'enciclica sul lavoro nel commento di..., Libreria Editrice Vaticana, Città del Vaticano, $1981,11$.

27. L.E., n, 13/3.

28. L.E., n. $7 / 2,3$.

29. L.E., n. 11/4.

30. L.E., n. 7/2, 3 y 13/3 y 4; CAMACHO, I., «El socialismo en la Laborem Exercens»: en AA.VV., Juan Pablo II y la justicia social, Razón y Fe, Madrid 1982, 50. 
dera ideología dominante en el capitalismo, porque aunque se le presenta bajo concepciones filosóficas defensoras de los valores humanos y de la civilización occidental, en realidad la fuerza dominante e impulsora de todo el sistema es una práctica materialista. De hecho todas sus estructuras económicas, sociales, culturales y políticas están cuidadosamente orientadas hacia el valor preferente del capitalismo: producir y tener más; ellas refuerzan la mentalidad del hombre económico, consistente en la combinación óptima de las variables constitutivas del hecho económico entre las que enumera el trabajo humano. Es, dice Osés, una idolatría de la riqueza individual, cuyos ilegítimos privilegios, derivados del derecho absoluto de propiedad, causan contrastes escandalosos y situaciones de dependencia y opresión ${ }^{31}$. Tal acusación de idolatría se repite también en el documento de Puebla que, a su vez, afirma que las estructuras creadas por el gran capitalismo está plasmado objetivamente el misterio del pecado ${ }^{32}$. El capitalismo se inspira en un humanismo cerrado a toda perspectivă transcendente, debido $\mathrm{a}$ su ateísmo práctico ${ }^{33}$.

No olvida que el materialismo dialéctico es como una consecuencia del materialismo práctico y fase avanzada del desarrollo de la filosofía materialista.

Hemos de tomar conciencia de este materialismo imperante en el sistema capitalista, de manera que no corramos el riesgo de que, mientras estamos sensibilizados «contra el materialismo abierto que elimina expresamente a Dios de la interpretación del mundo, no seamos sensibles al materialismo camuflado que elimina a Dios, en la práctica, de la interpretación del mundo» ${ }^{34}$.

El sistema comunista se interna más profundamente en el materialismo, puesto que refuerza el materialismo práctico con el dialéctico y con el histórico. Parece como si el Papa, al hablar de los elementos que hacen incompatible el cristianismo con el comunismo, diferenciara las siguientes clases de materia- lismo:

a.- El materialismo práctico consiste en una forma de actuar orientada por «un modo de valorar, por una jerarquía de bienes, basada sobre la inmediata y fuerte atracción de lo que es material» ${ }^{35}$.

31. L.E., n. 7; OsEs, J.M., «Reflexión crítica sobre el capitalismo»: Iglesia Viva (1982/9798) 57-58; VelasCo, D., «Reflexión crítica sobre el socialismo real»: Iglesia Viva (1982/97-98) 67.

32. Puebla, n. 281.

33. OsÉ, J.M., a.c. 49.

34. Osés, J.M., a.c., 60; SPIAZzI, R., L'enciclica sul lavoro: Laborem Exercens, Massimo, Milano 1981, 35.

35. L.E., n. 13/3; CAMACHO, I., «El socialismo en la Laborem Exercens»: en AA.VV., Juan Pablo II y la justicia social, Razón y Fe, Madrid 1982, 50. 
b.- El materialismo dialéctico o materialismo teórico, que lo presenta como una consecuencia del materialismo práctico y fase avanzada del desarrollo de la filosofía materialista y que consiste en «no entender al hombre, ante todo, como sujeto del trabajo y causa eficiente del proceso de producción, sino que es entendido y tratado dependiendo de lo que es material, como una especie de «resultante» de las relaciones económicas y de producción predominantes en una determinada época» ${ }^{36}$.

c.- El materialismo histórico que consiste en considerar la lucha de clases como el motor de la historia, «como la única vía para eliminar las injusticias de clase, existentes en la sociedad, y las clases mismas ${ }^{37}$, a través de la colectivización de los medios de producción que acabe con la explotación del trabajo humano ${ }^{38}$.

Partiendo del Evangelio del trabajo «justo, es decir, intrínsecamente verdadero y a su vez moralmente legítimo, puede ser aquel sistema de trabajo que en su raíz supera la antinomia entre trabajo y el capital, tratando de estructurarse según el principio expuesto más arriba de la sustancial y efectiva prioridad del trabajo, de la subjetividad del trabajo y de su participación eficiente en todo el proceso de producción, y esto independientemente de la naturaleza de las prestaciones realizadas por el trabajador» ${ }^{39}$. Pero para llegar a tal sistema «no se ve otra posibilidad de una superación radical de este error, si no intervienen cambios adecuados tanto en el campo de la teoría, como en el de la práctica, cambios que van en la línea de una decisiva convicción de la primacía de la persona sobre las cosas, del trabajo del hombre sobre el capital como conjunto de los medios de producción» ${ }^{40}$.

Pero ¿de dónde partir para llegar a ese sistema ideal? A este respecto me parece conveniente transcribir el siguiente párrafo de I. Camacho: «...en segundo lugar $-\mathrm{y}$ esto es lo más novedoso respecto a la doctrina social anterior - la Laborem Exercens propone no uno, sino dos puntos de partida para buscar esta alternativa: no sólo el capitalismo, como había sido lo normal hasta ahora, sino también el socialismo. Aquí surge la experiencia personal de Juan Pablo II en un país socialista, en contraste con las experiencias de todos los pontífices anteriores (y probablemente todos sus asesores), que han pensado la doctrina social desde el mundo capitalista. Hasta ahora el socialismo real había sido contemplado desde fuera, desde lejos, como algo en lo

36. L.E., n. 13/4; САMACHO, a.c. 50.

37. L.E., n. 11/3.

38. L.E., n. $13 / 4$.

39. L.E., n. 11/1.

40. L.E., n. 11/5. 
que apenas merecía la pena entrar. Esto no significaba (no siempre, al menos) una aceptación del sistema alternativo, el capitalista, pero sí se traducía en un esfuerzo unilateral por buscar un sistema renovado sólo desde este lado de la disyuntiva. En la Laborem Exercens el socialismo real, el colectivismo del Este europeo, se presenta como una realidad que también merece la pena estudiar por qué línea se puede transformar desde dentro. Esto es - pienso- una aportación novedosa, que hay que agradecer a la nacionalidad y a la mentalidad personal de Juan Pablo II. A la luz de este hecho es posible quizás comprender mejor por qué la doctrina social suele ser tachada de «procapitalista», aún cuando la mayoría de los documentos anteriores hayan procurado hacer una crítica simultánea de los dos sistemas».

\section{SOCIALIZACIÓN DE LA PROPIEDAD PRIVADA}

Desde una consideración realista, los medios capaces de cambiar el sentido y la lógica interna del capitalismo pasan por la socialización de la propiedad privada.

Está fuera de lugar y sería violentar el texto de la encíclica afirmar que la Laborem Exercens se levanta contra la propiedad privada. Defiende con claridad y energía la propiedad privada. Para ello recoge las argumentaciones de corte personalista que venían perfeccionándose en los documentos pontificios ya desde Pío XII. Sin embargo rechaza la actual distribución de la propiedad privada, tal como es defendida por las regulaciones civiles tanto de corte socialista como capitalista. No puede admitir la idolatría de la propiedad privada, concebida como un derecho absoluto generador de contrastes escandalosos y situaciones de dependencia y opresión. La enseñanza de la Iglesia «diverge radicalmente del programa del colectivismo, proclamado y realizado por el marxismo en varios países del mundo en los decenios que siguieron a la encíclica de León XIII; y también difiere del programa del capitalismo practicado por el liberalismo y por los sistemas políticos, que en él se inspiraron» ${ }^{41}$.

La encíclica aboga por una propiedad privada, pero socializada, que responda a la doble dimensión del ser humano: ser personal individual y social ${ }^{42}$.

Juan Pablo II habla de socialización de la propiedad. Ya había hablado

41. L.E. 14/2. OsÉs, J.M., a.c., 49; UNCITI, M. de, «La primera aproximación a la encíclica»: Iglesia Viva (1982/97-98) 7; TALIERCIO, G., «Il diritto «alla» propietà: Palestra del Clero 62 (1983) 98; GARCiA, M., «Conceptos claves de la Laborem Exercens»: en AA.VV., Juan Pablo II y la justicia social, Madrid 1982, 30.

42. L.E., n. 14; Molinaro, A., «Conflitti umani nel lavoro»: en AA.VV., Il lavoro per l'uomo, Città Nuova Editrice, Roma 1982, 51-52. 
antes Juan XXIII ${ }^{43}$. Aquí Juan Pablo II se apropia el vocablo «socialización», pero profundizando su significado.

Juan XXIII nos ofreció un concepto de socialización demasiado amplio e ideológicamente neutro. La Mater et Magistra se limitaba a una descripción de los hechos constatados. $Y$ éstos hablaban de una intensificación -en extensión y en profundidad- de las interdependencias sociales en las diferentes áreas de la vida. Describe el contenido que las corrientes económicas dominantes atribuían al vocablo «socializar»: paso de las empresas del dominio privado al público, por la tendencia natural a asociarse para la conquista de objetivos que superaban la capacidad y los medios de que disponen los particulares individualmente, como también un «reflejo» y causa de una creciente intervención de los poderes públicos» ${ }^{44}$.

Juan Pablo II, en cambio, utiliza el vocablo «socializar» en el sentido de cambio de estructura. Frente a la estructura privada prefiere la estructura socializada de la propiedad ${ }^{45}$, porque evidencia mejor el aspecto social del trabajo y de la propiedad. Pero atención, porque no hemos de identificar estructura socializada de la propiedad, a socialización de la propiedad, con propiedad estatal. La Laborem Exercens pone mucho cuidado en distinguir entre Estado y Sociedad, entre propiedad colectiva inherente al Estado y a los poderes públicos y propiedad colectiva inherente a la sociedad y a los grupos. La socialización de la propiedad o estructura socializada de la misma no solamente se opone a la estructura privatizada de la propiedad sino también a su estructura estatalizada. Juan Pablo II ve a la Sociedad - como distinta del Estado y de los poderes públicos- como sujeto capaz de poseer, ya considerada en su conjunto, como un todo, ya fraccionada en múltiples grupos. Muestra clara preferencia por los grupos como cuerpos intermedios con finalidades económicas, sociales y culturales ${ }^{46}$. Tales grupos, con capacidad efectiva de poseer, parecen insustituibles para conseguir la socialización de la propiedad, deseada por la encíclica. Y serán realmente efectivos solamente a condición de que se les reconozca el poder de titularidad de la propiedad de los medios de producción y «una efectiva autonomía en relación a los poderes públicos» ${ }^{47}$. Se refiere a una autonomía real de gestión, de iniciativa y de destino de la propiedad, del uso de los medios de producción y del fruto del trabajo hacia el bien

43. Mater et Magistra, n. 40-45.

44. Mater et Magistra, n. 46; «Presentación»: Iglesia Viva (1982/97-98) 8.

45. Laborem Exercens, n. 14, 15, 19.

46. Laborem Exercens, n. 14.

47. Laborem Exercens, n. 14. 
común: «en una colaboración leal y subordinada a las exigencias del bien común» ${ }^{48}$.

Bajo cierto aspecto demitiza la propiedad privada, puesto que no admite que se la convierta en la piedra de toque para enjuiciar los sistemas económicos, de manera que el capitalismo sea plausible porque defiende la propiedad privada, y condenable el comunismo porque tiende a suprimirla. No es que así quedemos sin criterio para enjuiciar los sistemas. Los da la encíclica, como ha quedado indicado ya anteriormente, resumiéndose todos ellos en que los sistemas deben orientarse hacia la personalización, a ayudar a las personas a ser más. Pero la encíclica deshace la ecuación propiedad privada=personalización, como si la propiedad privada fuera el único camino para obtener la personalización deseada.

Pero demitizar la propiedad privada no quiere decir ni renunciar a ella ni condenarla de manera absoluta. En contraste con el marxismo la Laborem Exercens no piensa que toda propiedad privada sea fuente de explotación, ni tampoco que su mera supresión lo solucione todo ${ }^{49}$. La Laborem Exercens admite tanto la propiedad privada como la estatal con la única condición de que toda forma de propiedad se ponga al servicio del hombre, de todo hombre, de forma que el hombre se sienta «sujeto activo y, por tanto, fin de todo el proceso productivo» ${ }^{50}$.

Sin embargo defiende la propiedad privada no en el sentido de propiciar el actual estarn de cosas, sino en la dirección que ya hace años venían indicando los documentos pontificios y que han subrayado vigorosamente el Vaticano II y la Populorum Progressio. Estos documentos exigen la extensión o difusión de la propiedad privada o de un cierto poder sobre las cncas a todas y cada una de las personas, de manera que sea efectivo ý una reaudad constatable «la realización del primer principio de este orden que es el destino universal de los bienes y su uso común» ${ }^{51}$. De aquí que, interpretando auténticamente el magisterio precedente, afirme que la Iglesia «nunca ha defendido co-

48. HECKEL, R.; "Continuità e rinnovamento»: en AA.VV., Laborem Exercens. L'enciclica sul lavoro nel commento di..., Libreria Editrice Vaticana, Città del Vaticano 1981, 138; A. FerRarI-Toniolo, «Soggettività del lavoro e proprietà»: en $I b$., p. 186-187.

49. САмАсно, I., «El socialismo en la Laborem Exercens»: en Juan Pablo II y la justicia social, Razón y Fe, Madrid 1982, 53; UNCITI, M. de, «Primera aproximación a la encíclica»: Iglesia Viva (1982/97-98) 8-10.

50. Laborem Exercens, n. 10; A. FerRARI-Toniolo, «Soggettività del lavoro e proprietà»: en AA.VV., Laborem Exercens. L'enciclica sul lavoro nel commento di..., p. 183; MoliNARO, A., «Conflitti יmani nel lavoro» en AA.VV., Il lavoro per l'uomo, Città Nuova Editrice, Roma 1982, 52; T 1 .....RCIO, G., "Originalità criștiana del diritto di propietà»: Palestra de' Clero 61 (1982) 1511-1512.

51. Laborem Exercens, n. 14/3. 
mo un derecho absoluto e intocable la propiedad privada. Al contrario, siempre lo ha entendido en el contexto más amplio del derecho común de todos al usar los bienes de la entera creación: el derecho a la propiedad privada como subordinado al derecho al uso común, al destino universal de los bienes» ${ }^{52}$.

Socializar la propiedad, cuando se habla del capitalismo, significa sacarla del contexto de la justicia conmutativa o, mejor, de la concepción habitual de la justicia conmutativa, para considerarla desde la óptica de la persona, de toda persona humana. Socializar la propiedad privada significa reconocer y actuar su «hipoteca social», puesto que "sobre toda propiedad privada grava siempre una hipoteca social, de manera que los bienes sirvan al destino universal que Dios los ha dado» ${ }^{53}$. Es otra de las expresiones acuñadas por Juan $\mathrm{Pa}$ blo II con la que subraya más fuertemente la «función social» de la propiedad.

Desde esta acentuación de la «hipoteca social» ac la propiedad podemos comprender otras afirmaciones más desacostumbradas sobre la propiedad: «Además, la propiedad según la enseñanza de la Iglesia nunca se ha entendido de modo que pueda constituir un motivo de contraste social en el trabajo. Como ya se ha recordado anteriormente en este mismo texto, la propiedad se adquiere ante todo mediante el trabajo, para que ella sirva al trabajo. Esto se refiere de modo especial a la propiedad de los medios de producción. El considerarlos aisladamente como un conjunto de propiedades separadas con el fin de contraponerlos en la forma del «capital» al «trabajo», y más aún realizar la explotación del trabajo, es contrario a la naturaleza de estos medios y de su posesión. Éstos no pueden ser poseídos contra el trabajo, no pueden ser ni siquiera poseídos por poseer, porque el único título legítimo para su posesión -y esto ya sea en la forma de la propiedad privada, ya sea en la de la propiedad pública o colectiva - es que sirvan al trabajo; consiguientemente que, sirviendo al trabajo, hagan posible la realización del primer principio de aquel orden, que es el destino universal de los bienes y el derecho a su uso común» ${ }^{54}$.

«Desde esta perspectiva, sigue siendo inaceptable la postura del «rígido» capitalismo, que defiende el derecho exclusivo a la propiedad privada de los medios de producción, como un «dogma» intocable en la vida económica». El pensamiento de la doctrina social de la Iglesia «se diferencia del programa del capitalismo, practicado por el liberalismo y por los sistemas políticos que se refieren a él. La diferencia consiste en el modo de entender el derecho mismo de la propiedad. La tradición cristiana no ha sostenido nunca este derecho co-

52. Laborem Exercens, n. 14/2.

53. Puebla, Documenti... etc., Editrice Missionaria Italiana, Bologna 1979, n. 1.281.

54. Laborem Exercens, n. 14/3. 
mo absoluto e intocable. Al contrario, siempre lo ha entendido en el contexto más amplio del derecho común a todos a usar los bienes de la entera creación: el derecho a la propiedad privada como subordinado al derecho al uso común, al destino universal de los bienes» ${ }^{55}$. Consiguientemente «el principio del respeto al trabajo, exige que este derecho (el de propiedad) se someta a una revisión constructiva en la teoría y en la práctica» ${ }^{56}$.

Y socializar la propiedad privada, frente al comunismo, significa defender el recto concepto personalista de la propiedad, finalidad personalizante que no se consigue «mediante la eliminación apriorística de la propiedad privada de los medios de producción» ${ }^{57}$, porque si la propiedad tiene un sentido social también lo tiene personal-individual, desde el momento que la persona es un ser individual y social. La socialización responde mejor a esa doble vertiente de la persona humana.

Socializar la propiedad, frente al comunismo, significa no confundirla con la colectivización defendida y actuada por el comunismo y consistente en la «transferencia de los medios de producción de las manos privadas a las de la colectividad $\gg{ }^{58}$. La socialización de la propiedad se opone a la colectivización total de la propiedad en manos del Estado. Además la socialización posee fuerza y medios correctores de los riesgos que encierra la colectivización. Ésta puede llevarse a cabo rectamente y en conformidad con el primado del trabajo, pero también puede convertirse en abusiva «reivindicando un monopolio de la administración y disposición de los medios de producción que no se para ni ante la violación de los derechos fundamentales del hombre» ${ }^{59}$, porque en la colectivización «los medios de producción dejan de ser de un determinado grupo social, o sea de propietarios privados, para pasar a ser propiedad de la sociedad organizada, quedando sometidos a la administración y al control directo de otro grupo de personas, es decir, de aquellos que, aunque no tengan su propiedad por más que ejerzan el poder dentro de la sociedad, disponen de ellos a escala de la entera economía nacional, o bien de la economía local» ${ }^{60}$.

La socialización goza de capacidad para corregir los riesgos que corre la

55. Laborem Exercens, n. 14/2.

56. Laborem Exercens, n. 14/3,6.

57. Laborem Exercens, n. 14/6.

58. Laborem Exercens, n. 11/4.

59. Laborem Exercens, n. 14/7.

60. Laborem Exercens, n. 14/6; Cfr. SpIAzzI, R., L'enciclica sul lavoro. Laborem Exercens, Massimo, Milano 1982, 32-33; Perone, G., "I diritto dell'uomo del lavoro»: en AA.VV., Il lavoro per l'uomo, Città Nuova Editrice, Roma 1982, 83-85; CAMPANINI, G., «Lavoro e società»: Rivista di Teologia Morale (1981/52) 598. 
colectivización, porque la socialización no se consigue naua más que cuando se haya «asegurado la subjetividad de la sociedad», es decir, "cuando cada uno, en base al propio trabajo, pueda considerarse a pleno título como copropietario del gran banco de trabajo en el que se emplean todos». Para ello propone: «Un camino para conseguir esa meta podría ser la de asociar, en cuanto sea posible, el trabajo a la propiedad del capital y dar vida a una rica gama de cuerpos intermedios con finalidades económicas, sociales, culturales: cuerpos que gocen de una autonomía efectiva respecto a los poderes públicos, que persigan sus objetivos específicos manteniendo relaciones de colaboración leal y mutua, con subordinación a las exigencias del bien común y que ofrezcan forma y naturaleza de comunidades vivas; es decir, que los miembros respectivos sean considerados y tratados como personas y sean estimulados a tomar parte activa en la vida de dichas comunidades» ${ }^{61}$.

Pero para dejar el camino abierto a la socialización de la propiedad son necesarias no pocas y profundas reformas. Tantas que la doctrina social de la iglesia «diverge radicalmente del programa del colectivismo, proclamado y realizado por el marxismo en varios países del mundo en los decenios que siguieron a la encíclica de León XIII» ${ }^{68}$. Se observa una graduación en el juicio negativo pronunciado por la encíclica sobre la posición de ambos sistemas en tema de propiedad. Mientras del capitalismo afirma simplemente que la doctrina de la iglesia «difiere», sostiene, en cambio, que la misma «diverge radicalmente» del punto de vista sostenido por el marxismo. Tal divergencia radical consiste en que la doctrina social de la Iglesia defiende la propiedad privada, interpretada y acentuando más que nunca su sentido social y el comunismo se propone anular cualquier vestigio de propiedad privada.

Así, pues, debe quedar claro que, por lo que se refiere a la propiedad privada, la doctrina social de la Iglesia «ha buscado y busca con todo el esfuerzo asegurar siempre el primado del trabajo» y, por lo mismo, la subjetividad del hombre en la vida social y, especialmente en la estructura dinámica de todo el proceso económico» ${ }^{62}$.

\section{Z. HERRERO}

61. Laborem Exercens, n. 14/7.

62. Taliercio, G., «Originalitá cristiana del diritto di proprietà»: Palestra del Clero 61 (1982) 1507-1513. 